\title{
Origin of Petroleum: A New Theory of Its Formation
}

\author{
Mustafa Mahmoud Mawad \\ Retired, Jeddah, Saudi Arabia \\ Email: mustafamawad@hotmail.com
}

How to cite this paper: Mawad, M.M. (2020) Origin of Petroleum: A New Theory of Its Formation. Journal of Power and Energy Engineering, 8, 63-72.

https://doi.org/10.4236/jpee.2020.88005

Received: December 24, 2019

Accepted: August 22, 2020

Published: August 25, 2020

Copyright $\odot 2020$ by author(s) and Scientific Research Publishing Inc. This work is licensed under the Creative Commons Attribution International License (CC BY 4.0).

http://creativecommons.org/licenses/by/4.0/

\begin{abstract}
Petroleum is not a production of direct transformation of organic material into kerogen or oil. Sea organics can't form such huge oil fields, since these sea creatures will either be consumed by bigger ones or decayed after few days. Farther more these sea animals consist of several components, such as proteins, scales, bones, and minerals, which could not be changed into oil. These should be seen as oil contamination, and we know that oil is relatively very pure hydrocarbon. Using methane as a primary component in the process of petroleum formation is a logical possibility for several reasons. Methane is quite abundant in nature, since the creation of the globe until these days. Furthermore, methane could be transformed into the different components of the crude oil by polymerization. Methane is highly pure hydrocarbon producing highly pure oil components. Methane could migrate easier than kerogen, and be collected in the methane traps (oil traps), since it behaves like water seeping into the lower beds. By mild heat and pressure at the depth methane polymers (oil components) will be formed. Oil is considered to be formed in-situ and not as mentioned in the organic theory, migrating from the kitchen to the oil trap. All the above point of views will be discussing in detail. Alternative ideas which are more logical and more acceptable will be suggested, and it will be the new progress concerning the origin of petroleum, its exploration, and localization.
\end{abstract}

\section{Keywords}

Methane, Polymerization, Hydrocarbons, New Theory

\section{Introduction}

Since the beginning of the last century, the theory of the origin of petroleum was 
not revised, and all petroleum geologists are accepting, more or less, the organic origin theory, even though it has many presumptions and unsupported conclusions.

In his text book "Geologic Models of Petroleum Entrapment" [1] Dr. King Magara, stated, "The significant developments of the concepts and technology of petroleum geology in the last several decades, many ideas are still quite controversial. We would need more time to sort them out based on the increased amount of new data and experience. In addition, Dr. Magara stated, I chose a set of concepts, which I favour from my own scientific standpoint and experience".

In addition to that, we always read in the petroleum books and papers, uncertain words describing the reliability of the supportive date, such as probably, assuming, predicted, could be, likely... etc. Add to this the words that describe the organic origin of the oil are rather exaggerated or not conformable with the nature of the rocks and the organic maters. The migration of this heavy and sticky kerogen through the impermeable limestone, shale, and its movement from the kitchen to the trap is not acceptable at all. I suggested that oil is formed in-situ due to the polymerization of methane gas to form the leaner hydrocarbons (the crowd oil).

\section{Petroleum Formation [2]}

Petroleum formed under earth's surface by the decomposition of marine organisms. The remains of tiny organisms that live in the sea, and, to a lesser extent, those of land organisms that carried down to the sea by rivers and of plants that grow on the ocean bottoms, enmeshed with the fines and silt that settle to the bottom in quiet sea basins. Such deposits, which are rich in organic materials, become the source rocks for the generation of crude oil. The process began many millions of years ago with the development of abundant life, and it continues to this day. The sediments grow thicker and sink to the sea floor under their own weight. As additional deposits pile up, the pressure on the ones below increases several thousand times, and the temperature rises by several hundred degrees. The mud and sand harden into shale and sandstone; carbonate precipitates and skeletal shells harden into limestone; and the remains of the dead organisms transformed into crude oil and natural gas. Once the petroleum formed, it flows upward in earth's crust because it has a lower density than the brines that saturate the interstices of the shale, sand, and carbonate rocks that constitute the crust of earth. The crude oil and natural gas rise into the microscopic pores of the coarser sediments lying above. Frequently, the rising material encounters an impermeable shale or dense layer of rock that prevents further migration; the oil has become trapped, and a reservoir of petroleum formed. A significant amount of the upward-migrating oil, however, does not encounter impermeable rock but instead flows out at the surface of the Earth or on to the ocean floor. 


\section{Methodology}

That last paragraph about the petroleum formation copied from an article from the internet. It carries the same ideas as all other books. The idea of having petroleum formed in such a way faces many unacceptable and controversial points that have no concrete answers.

To form such huge amounts of petroleum we need tremendous amounts of organic materials deposited and barred in a very short time, otherwise, these organic materials will be decomposed and no soft parts will remain to form oil. These organics are mainly zooplanktons and/or phytoplankton which created by God to be at the base of the nutrition pyramid, feeding the hatched fishes, corals polyps, three of the largest sea creatures namely the blue wheal, wheal shark, and the sea devil. These planktons will be consumed totally and nothing will be left to form oil. If some were left and deposited at the sea bottom, huge numbers of deep-sea creatures are there to feed on them.

In addition, the organics, in the sea do not precipitate separately but contemporaneously with the sediments. Therefore, the organics will be distributed and disseminated within the sediments, and only the lower ones will be subjected to the heat and pressure, considering that their soft parts still existed and not decomposed. Therefore, to preserve the organic materials and prevent them from decomposition, the process of deposition and burial of the organics should be synchronized and very fast.

A good example of good preservation of soft parts within their shells is the Burgess Shale [3], located in the Canadian Rockies of British Columbia. That field is famous of its exceptional preservation of the soft parts of its fossils in the black shale. This is probably due to the fast slumping of the detached tops of the lime stone cliffs to the bottom to cover the ponds and the shale, and protects the life stocks from decomposition.

The organic theory suggests that organic materials, under high pressure and temperature will be transformed into kerogen, within the carbonates. Later, this kerogen will migrate through the pores and fractures of the limestone till it reaches the surface of the earth or trapped into an oil trap. Limestone is not a good porous rock, and is not a permeable rock to permit this sticky kerogen and solid hydrocarbons $\left(\mathrm{C}_{27} \mathrm{H}_{56}\right)$ migrates freely to its final destination, and the forces that moves the kerogen are quite ambiguous.

Therefore, if Kerogen was formed in the limestone, some of it should be trapped inside as an interstitial liquid indicating the track of its migration. Actually, I have never seen any oil trapped in limestone during my long work as field geologist in Saudi Arabia indicating the track of the oil migration. However, oil, which extracted from the oil limestone beds, was not formed because of decomposition of living organisms. (This will be explained later).

All petroleum geologists advocate that the main sources of oil are either limestone or shale [4]. That is partially right, but not the real fact. (Later this also will be discussed as I will postulate a new idea that will explain all that). 
If the shale considered as one of the main sources of petroleum and contains oil, then the mudstones, siltstones and clay stones should be also sources of petroleum and contain oil. All these rocks should contain oil with the same degree but we see that only the shale contains oil. (This also will be discussed later and discloses the reason behind that).

If we consider limestone and the shale are porous or fractured to contain the oil, it is evident that at great depths and due to the great pressure and heat, all these features will be obliterated and sealed. Then the so-called kerogen will not be able to migrate and will be locked in the mother rock. Actually, no kerogen was formed as a transformation of organics in these rocks. It is only filling the cracks and fractures within these rocks, which indicate that kerogen is formed in-situ as polymerization of methane. The rocks her (shale and limestone), consider as an oil trap and not as a mother rock. i.e., the rocks are the recipient and not the donor.

When the organic theory was established, the theorists thought that the seas lives do not exceed the depth of eighty meters, and no living organisms exist below that depth. Now after visiting these depths with special designed submarines, they found that large numbers of living organisms are living at all depths they visited, and these organisms feed on anything that sinks from the surface.

A baby whale killed by a killer whale ate only the tong and the rest of the body sunk to a depth of about 300 meters. After one year the carcass was visited, all the soft parts were consumed and only the skeleton was left [from a documentary film]. No organic materials left to form any oil. That what would happen to any organisms that will sink to these depths, and no organics will be left to form, oil.

Taphonomists [5] are those whom study decaying organisms over time and how they become fossilized. Archaeologists study taphonomic processes in order to determine how plants and animals remains accumulated and preserved within the archaeological sites. From a paper from Wikipedia about Taphonomics [5] study of the fossils and how they were differentially preserved, they elaborated that the bio mineralizing organisms have a far greater chance of being represented and preserved than the soft bodied organisms. These soft-bodied organisms may form $30 \%$ to $100 \%$ of the biota; however, they will NOT be preserved probably, due to disintegration of the soft parts, and completely disappeared if they have no hard parts. That what will happen to all the planktons, they lose their soft parts when they were moving up and down in the upper layer of the ocean, and the remaining hard parts (if any existed) will settle down to the ocean floor to form one of these two main rocks, chalk or ooze.

As we know, oil is formed at all ages, from the Precambrian (4500 billion of year ago) to the recent. Living organisms starts to appear at the Cambrian (2500 billion of years ago), how this old oil was formed. It should be formed from something other than living organisms or kerogen.

To support the theory of oil migration, from the kitchen to the trap, without 
losing any of its components, they suggested that oil is formed in the kitchen as one hydrocarbon named kerogen. This kerogen is a hydrocarbon consists of about 27 carbon atoms. When kerogen reaches the oil traps and subjected to high pressure and temperature (exceeds 500 degrees), it will be cracked to smaller hydrocarbons and form oil with all its components.

This theory is quite unacceptable and lack of many scientific pointes. Kerogen is a solid hydrocarbon (has 27 carbon atoms). How we are going to move such solids from the source to the trap (we need a conveyer belt or heavy equipment). Other point is the need of a very high temperature (up to 500 degree) to crack the kerogen. This will not be attained except at very high depths. We need an explanation for how the oil found close to the surface was formed.

\section{Result and Discussion}

From the above discussion we realized, neither the limestone nor the shale can be the direct source of kerogen since there are no enough organic materials associated with them to form those huge amounts of oil. In addition, these two kinds of rocks do not have good permeability to facilitate the migration of the formed oil to its final destination.

The obvious question that comes to the surface is what are the alternatives? The organic materials, as we all know now, will decomposed by the anaerobic bacteria to form methane gas (only the fats).This methane although it is lighter than the air, (as it is published in all the organic chemistry textbooks) [6] [7], I found that it has the tendency to behave like water especially at high pressure and always stays close to the earth surface, at the lowest areas. However, if this rock is permeable, the gas will penetrate the surface and ascends till it reaches a competent layer or fractured rock or an oil trap where it will accumulate. When it reaches greater depths and subjected to high temperature and high pressure this methane, (the so-called natural gas, since it is not pure methane but a mixture of two or three alkane gases, namely ethane and propane), will undergoes a chain of reactions to forms gas alkanes, liquid alkanes, waxy alkanes as well as solid alkanes, and also cycloalkanes known as naphthenic (the crude oil). This process of transformation of simple hydrocarbons to a more complicated ones is known as polymerization. From methane and ethane all the petroleum components could be generate, when these gases are subjected to enough heat and pressure. No doubt, this chemical process (polymerization) will change the simple molecular structure of methane to its final structure which is a mixture of alkanes when it is subjected to different pressures, temperatures, and with the help of catalytic actions of some minerals that encountered. This process is reversible, and a process called cracking will convert the so complicated components of alkanes and alkenes to simpler components. Never the less, this process (cracking) is very difficult since it needs great amount of energy, catalysts and continuous removal of the formed products to prevent reversible reaction. Therefore it is easier to form petroleum from synthesizing the simple alkanes, namely methane, to more complicated ones than to crack the very complicated kerogen 
to the simpler petroleum components.

The reaction, polymerization, is following this formula [7];

$$
\mathrm{C}_{\mathrm{n}} \mathrm{H}_{2 \mathrm{n}+2}
$$

\begin{tabular}{|c|c|c|c|c|c|}
\hline \multicolumn{6}{|c|}{ ALKANES } \\
\hline \multicolumn{2}{|c|}{ GASES } & \multicolumn{2}{|c|}{ LIQUIDS } & \multicolumn{2}{|c|}{ SOLIDS } \\
\hline FORMULA & NAME & FORMULA & NAME & FORMULA & NAME \\
\hline $\mathrm{CH}_{4}$ & Methane & $\mathrm{C}_{5} \mathrm{H}_{12}$ & Pentane & $\mathrm{C}_{18} \mathrm{H}_{38}$ & Octadecane \\
\hline $\mathrm{C}_{2} \mathrm{H}_{5}$ & Ethane & $\mathrm{C}_{6} \mathrm{H}_{14}$ & Hexane & $\mathrm{C}_{18} \mathrm{H}_{40}$ & Nonadecane \\
\hline $\mathrm{C}_{3} \mathrm{H}_{8}$ & Propane & $\mathrm{C}_{7} \mathrm{H}_{16}$ & Heptane & $\mathrm{C}_{19} \mathrm{H}_{42}$ & Eicosane \\
\hline \multirow[t]{10}{*}{$\mathrm{C}_{4} \mathrm{H}_{10}$} & Butane & $\mathrm{C}_{8} \mathrm{H}_{18}$ & Octane & & \\
\hline & & $\mathrm{C}_{9} \mathrm{H}_{20}$ & Nonane & & \\
\hline & & $\mathrm{C}_{10} \mathrm{H}_{22}$ & Decane & & \\
\hline & & $\mathrm{C}_{11} \mathrm{H}_{24}$ & Undane & & \\
\hline & & $\mathrm{C}_{12} \mathrm{H}_{26}$ & Dodicane & & \\
\hline & & $\mathrm{C}_{13} \mathrm{H}_{28}$ & Tridecane & & \\
\hline & & $\mathrm{C}_{14} \mathrm{H}_{30}$ & Tetradecane & & \\
\hline & & $\mathrm{C}_{15} \mathrm{H}_{32}$ & Pentadecane & & \\
\hline & & $\mathrm{C}_{16} \mathrm{H}_{34}$ & Hexadecane & & \\
\hline & & $\mathrm{C}_{17} \mathrm{H}_{36}$ & Heptadecane & & \\
\hline
\end{tabular}

where:

$\mathrm{C}=$ Carbon atomes.

$\mathrm{H}=$ Hydrogen atomes.

$\mathrm{n}=$ Number of carbon atomes.

This reaction will form all the oil hydrocarbons, as presented in the table above. The first group is the gas hydrocarbons, while the second one presents the liquid ones, and the third one demonstrates the solid hydrocarbons.

\section{Sources of Methane and Sulpher}

\subsection{Source of Methane}

Are the amounts of produced methane capable of producing all that huge amounts of oil?

Methane, generated from different sources,

1) The decay of only some parts of once was living organisms,

2) Cosmic methane.

3) Volcanic methane.

That methane is the very substance that becomes the primary component which crude oil will be formed. Millions of years, geologic stress and heat had transformed the methane into mixture of alkanes. This mixture ranging from one carbon to 30 or 40 carbons (following this general formula $\mathrm{C}_{n} \mathrm{H}_{2 n+2}$, where $\mathrm{C}$ 
is the carbon atoms, and $\mathrm{H}$ is the hydrogen atoms, and $\mathrm{n}$ is the number of the $\mathrm{C}$ atoms), which is the so called the crude oil. If it is very simple and composed only of the gaseous alkanes it will forms the so called the natural gas.

This methane generated in different ways. The main and most effective one is the decomposition of only small parts of the organic materials (the fats only). Methane also formed during the formation of the solar system (cosmic methane), since it was found almost in all planets and their moons. It was covering the glob with a very thick layer. It is also associated with the volcanic gases.

The presences of methane as inclusion in the diamond support that hypothesis. From my point of view, diamond formed when methane heated to a very high temperature in the absence of oxygen during the formation of the first deep-seated volcanic rocks. Methane decomposed to a very fine and pure carbon. This carbon when subjected to a very high pressure and temperature and slow cooling and recrystallization, diamond will be formed. Nevertheless, if the cooling was very fast, then graphite or graphite schist will be the final product. Inclusions of methane, was found in the diamond. These inclusions incorporated later and during the last stages of recrystallization, and they will be of later stages. If these gases were associated and contemporaneous with the old rock formations they will be changed into carbon and then to diamond, and no methane inclusion should be existing in the diamond. All of that will support the cosmic origin of methane which will be polymerized later to petroleum. The reaction of methane to synthesize the different oil components will support the abiogenic origin of petroleum with different thoughts.

As we indicated before. Methane generated in great quantities during the global formation. After that, methane started to forms from different sources, through the fermentation of the organic materials in many different places. These sources are extracted from an internet paper published by GISS [8]. In this paper, they recorded only the methane emitted by each source, but the annual global production is not listed. Never the less, from reading through many papers, I estimated that the global emission of methane is about 50 to 90 million tons pare year. The current estimates by GISS. for each source, "although some uncertainties remain" is: the largest source is wetlands $22 \%$, irrigated rice paddies $12 \%$, domestic ruminant animals $10 \%$, methane hydrates $3 \%$, termites $4 \%$, animals waste $5 \%$, sewage treatment $5 \%$, landfills $6 \%$,biomass burning $8 \%$, coal and oil mining $19 \%$.

From these numbers, it is evident that the amounts of methane produce every year and for millions of years, (regarding that these amounts start with lesser amounts, and raised up, and still rising to form a major global hazard), are more than enough to form the great amounts of petroleum. Add to that, the generated methane could be a good source of fuel for the future or even for more petroleum fields, (but we have to wait for another millions of years).

This new theory of petroleum formation seems to be more acceptable since it gives us more reliable explanation for how oil was formed. Add to that we can 
explain now how the oil was formed in the igneous rocks, and why we always find oil associated with gases, water, and sulpher.

\subsection{Source of Sulpher}

Oil is always pure hydrocarbons with sulpher as byproduct, which derived to the oil as dissolved $\mathrm{H}_{2} \mathrm{~S}$ in water. At depth $\mathrm{H}_{2} \mathrm{~S}$ is oxidized to form sulpher.

\section{Methane Properties}

As evidences for why methane behaves like water, and due to the lake of financial supports and laboratory facilities, i established very simple experiments to prove that.

The first; I used two small and light balloons. The first one filled with methane, and the second was filled with atmospheric air using hand pump to avoid adding more carbon dioxide and water vapor. The two balloons were dropped from about three meters high. The first one reached the room floor faster and with a quite study move, while the second one was moving down very slowly with an up and down move affected by the AC. air stream. Also, the first one stayed intact to the floor but not the second one. This indicates that the gas in the first one (methane) is heavy and has the tendency to be close to the lower point.

The second experiment, it was also very simple one. I used six meters PVC tubing with three inches diameters. The pipe was sealed from both ends and I drilled three holes, one at the middle of the pipe and one at each end. A small nozzle was attached to each hole. The pipe put in the vertical position and the gas (methane) pumped through the middle nozzle. Two flames hocked close to the upper and the lower ones. After few seconds the lower nozzle set on fire while the upper one did not. I pumped the gas for few minutes and no flames appeared from the upper one only from the lower one.

This experiment and the first one indicates that the methane gas moved downward and not upward, which means that methane has the tendency to be close to the lower surfaces. If this surface is permeable the gas will penetrate it and seeps into the ground.

I have more evidences to support this observation but all of them are either daily observations or personal communication.

\section{Conclusions and Recommendation}

Based on the above studies, I established five properties for the primary components to be genuine and could forms petroleum without failing to answer any question. These properties are:

1) Consists of pure hydrocarbon.

2) Produces in nature extensively.

3) Emigrates and localizes easily.

4) Exists in nature at all ages. 
5) Transforms to petroleum hydrocarbon.

If we subject these properties to methane, it will be the best primary component to form oil other than the organics or the calcium carbides.

The shale and the limestone are not the main source of oil, but they considered as reservoirs where the methane was emplaced, and during their alteration, "any rock could be a target for oil explorations if the rock is porous, fractured, sheared or fissile like shale", methane altered to oil affected by the regional heat and pressure. This methane could be generated from these rocks, if they consisted of organics, or be transported from other sources but they are not the main sources of oil.

Shale, mud stone, clay stone, and silt stone, consists mainly of clay minerals. If shale is considered as source rock, the other rocks should also be the same. Oil found only in shale because it is fissile and contains many cleavage planes facilitates the inhabitants of methane which will be polymerized later to form oil. This is the reasons why oil is found in shale and not in the other similar rocks. This new theory of petroleum formation seems to be more acceptable since it gives us more reliable explanation for how oil was formed. Add to that we can explain now how the oil was formed in the igneous rocks, and why we always find oil associated with gases, water, and sulpher.

Concluding this study, I recommend that methane should be used as a primary component for the formation oil. Methane will infiltrate to the lowest earth layers, and accumulates in any kind of rock as long as it is either fractured or porous "methane traps". If methane is formed in wet lands, it will be associated with water, sulfuric acid, and very minor living organisms. Later on, methane will be polymerized to oil and the sulfuric acid will be oxidized to sulpher, forming the so called the biter oil. If methane is formed from a dry source such as volcanic methane, the formed oil will be very poor in sulpher, and we will have the so called the sweet oil. At the suitable conditions "good pressure and temperature" methane will be polymerized to the different alkanes, and the crowd oil will be the final product. If methane is a young one or did not face these suitable conditions, it will form only the natural gas.

\section{Conflicts of Interest}

The author declares no conflicts of interest regarding the publication of this paper.

\section{References}

[1] Magara, K. (1978) Compaction and Fluid Migration: Practical Petroleum Geology. Elsevier Scientific Publication.

[2] Gold, T. (1985) The Origen of the Natural Gas and Petroleum, and the Prognosis for Future Supplies. Annual Review of Energy, 10, 53-77. https://doi.org/10.1146/annurev.eg.10.110185.000413

[3] Wikipedia, the Free Encyclopedia: Burgess Shale. http://en.wikipedia.org/wiki/Burgess Shale 
[4] Wikipedia, the Free Encyclopedia, Oil Shale. http://en.wikipedia.org/wiki/Oil shale5

[5] (2009) Methane: Sources and Emissions. http://www.epa.gov/methane/sources.html

[6] Mortimer, C.E. Chemistry. 5th Edition, Wadsworth Publication Company, Belmont.

[7] Morrison, R.T. and Boyd, R.N. Organic Chemistry. 3rd Edition, New York University, Allyn, and Bacon, Inc., Boston.

[8] GISS (2009) Institute of Climatic and Planets. Global Methane Inventory. http://giss.nasa.gov/education/methane/cycle.html 